\title{
Flippin' Education: a new pedagogy for paramedic students?
}

Abstract

This article presents a case study in which the author piloted the flipped classroom on a cohort of Paramedic Science students at a UK higher Education Institution. The flipped classroom will be explained alongside the rationale for considering it as a good pedagogical addition for Paramedic students. As a new pedagogy, the flipped classroom will be considered against what is currently known about learning theories and teaching styles. There are potential drawbacks to this method of teaching and learning and these will be discussed, as will suggestions to mitigate these drawbacks. Finally, the impact upon the students will be considered and the author will comment on the pilot and what this means for Paramedic education in the future.

Peter Phillips, Practice Fellow and Programme Lead Paramedic Science, Bournemouth University Bournemouth University, Christchurch Road, Bournemouth, BH1 3LT pphillips@bournemouth.ac.uk

01202962759

Key Words

Flipped classroom, education, pedagogy, paramedics, deep learning

Key Points

Flipped classroom is an emerging but promising teaching method

Flipped classroom can help promote deep learning in paramedic students

Social and constructivist learning can be used within the flipped classroom

Word Count - 2929 
The modern era of technology has opened up a raft of opportunities to innovate teaching and introduce new ways of teaching and learning that could increase engagement, increase students' abilities to critically think and to autonomously learn. The focus of this article will be the piloting of a flipped classroom on a Paramedic Science Degree, and the extent to which the flipped classroom may be valuable in paramedic education. The article will highlight the specific issues that the flipped classroom was designed to address, the design of the teaching method including the advantages and disadvantages, and evaluation of the teaching.

\section{What is 'Flipped Classroom'?}

More traditional methods of teaching teach the basics of a concept during classroom time and the student is expected to learn more deeply about the concept in self-directed study time. The basis of flipped classroom is that students learn the basics of a concept in their own time before attending class. Therefore, class time is used to explore a concept more deeply, ideally in a seminar facilitated by the lecturer (Abevsekera and Dawson, 2015). In this case the author used a fifteen minute podcast as the learning that students needed to do before attending class. The podcast was produced by the author, therefore it was tailored specifically for the needs of the students. However, it would be acceptable to use a podcast that is already available on the internet. In addition, there was a crib sheet produced that had links to websites and further reading should the student wish to access the same information in a written format, or read further into the subject before class. The flipped classroom as a concept is one that the author felt has a large potential in the paramedic curriculum and so it was piloted for a session on a cohort of level 5 paramedic students.

\section{Why might the flipped classroom be suitable for paramedic education?}

The flipped classroom was designed with a number of issues in mind. There is a need to encourage students to be critical thinkers, autonomous learners and reflective in order to operate as a competent paramedic. In addition, there is a disparity in knowledge and ability within the cohort, partly caused by a large difference in experience and knowledge before commencing the course. Some students had a lot of experience in the ambulance service, whereas others had no, or very little, experience in healthcare. This results in potential disengagement of students if the material is pitched at too high or too low a level for a particular student. It causes some students to get frustrated at other students who are asking questions far above their knowledge level, and vica versa. The flipped classroom helps to address this problem because it ensures that, providing all students do the pre-learning, they all come to the lecture with the same level of knowledge from which to build. In this way it seems it would help to engage all students and give all students a chance to contribute in the seminar rather than the same people contributing all the time. Sankoff (2014) supports this view, highlighting that modern students, for one reason or another, are becoming increasing difficult to engage by traditional teaching methods. He summarised that the flipped classroom helps to both engage students and inspire them. This study was conducted upon a cohort of Law students, however many of the challenges may be the same because both are vocational courses with professional considerations to take into account. Mok (2014) also supports the hypothesis that students can be engaged more effectively using the flipped classroom.

As with many cohorts, there are a number of students with additional learning needs (ALN), mostly dyslexic students. Most of these students are older students who have recently been diagnosed and 
therefore have struggled in traditional education. Teaching methods that do not meet the needs of an individual dyslexic student will be likely to disengage them and disadvantage them unnecessarily. Specific difficulties for some dyslexic students are the colours used in a powerpoint, amount of writing on a powerpoint, being strong orally but poorer when writing and sometimes needing more time to digest and process information (Mortimore and Crozier 2006). Using a flipped classroom with a podcast seems like it may be a good way to approach teaching this group of students. The medium used for pre-learning can be changed. In this pilot a podcast was used which may be a more effective way for a dyslexic student to learn than looking at writing. In addition, the student can listen to the podcast as many times as needed to digest the information. They can stop the podcast to take notes, they can listen to the podcast in smaller chunks over a longer period of time if they find that helpful. Therefore, it is hoped that the student with ALN can attend the lecture having not been disadvantaged in their learning and with the same level of information as other students. Evidence exploring this specific issue is very limited, however. Abevsekera and Dawson (2015) whilst acknowledging this fact highlight that the flipped classroom retrofits what we already know about teaching and learning. However, they conclude that much more specific research is needed.

It is thought that different students learn differently (Ramsden 2003), that is they have different learning styles. Some learn more effectively through visual mediums such as powerpoint presentations and handouts. Others learn better through listening, such as debates, discussion or questions and answers. Some learn better through doing, such as practising a skill and implementing theory in a practical setting. Many students have a mix, to a greater or lesser degree, of learning styles so it is important to be aware of these and vary the delivery of information appropriately (Ramsden 2003). The flipped classroom pilot was designed predominantly with a podcast. However, there was supporting material which had links to websites and worksheets so that the same information could be accessed in a variety of ways. This approach is hoped to have satisfied a variety of learning styles. This could probably have been made more engaging by adding video content to the pre-learning materials. This is called a vodcast and enables students to both listen to the podcast and watch a video related to it at the same time. This would help to enrich the information being provided and offer further opportunity for students with different learning styles to get the most out of the pre-learning material. A drawback of this is that it would be even more time consuming to produce and requires more technical knowledge.

It is crucial that the modern paramedic has the ability to critically think, analyse and make good clinical decisions. To do this the teaching method must be one that encourages deep learning. Ramsden (2003) describes deep learning as an approach to learning where students look at meaning behind information, link new ideas to previously learned ideas and put it into a context. This type of learning will supply the paramedic student with the skills to analyse information, critique it and apply it in their own practice. Danker (2015) explored whether the flipped classroom can encourage deep learning. She found that the flipped classroom encouraged active rather than passive learning and that students did indeed have a greater understanding of the material. This study looked at large group lectures, whereas the paramedic cohort is a small group of thirty students. However, it could be concluded that the potential is even greater in a smaller group to achieve deep learning. Mok (2015) supports this view finding that, when using flipped classroom, students took an autonomous approach to their learning. This active approach is sure to encourage deep learning. In addition, it is crucial that paramedic students have the skills to learn for the rest of their career and 
implement their new learning into their practice. Therefore, it seems that the flipped classroom has the potential to embed the skills of lifelong and autonomous learning in paramedic students.

\section{Learning theories}

Constructive alignment is important when designing a lecture to ensure that the ILOs, teaching method, learning style and assessment are all aligned to achieve the desired outcome (Ramsden 2003). It is pertinent, therefore, to consider the learning theory that may be used when designing the flipped classroom. It seems that the flipped classroom, depending upon the design, could be used with a number of learning styles. However, Brandon and All (2010) highlight the clear parallels between a constructivist learning style and encouraging deep learning. Constructivist learning is the process whereby students construct their own knowledge, rather than simply acquiring it from the lecturer. It requires the student to evaluate and analyse information, put it alongside previously learned information and apply it. It requires active learning and as such encourages students to analyse and evaluate, rather than simply describe and explain (Brandon and All 2010). So it can be seen that constructivist learning encourages the same values and skills that are important for paramedic students to possess. A key to constructivist learning is that the lecturer can provide information to 'scaffold' the creation of knowledge (Brandon and All 2010). The flipped classroom approach can provide this, in this case a podcast, which gives basic information upon which the student can build, analyse, discuss and apply. The discussion takes place in the classroom where students and their peers, facilitated by the lecturer, create their own knowledge. Abevskera and Dawson's (2015) point that much of the research is focussed upon retrofitting the flipped classroom to learning styles is pertinent here. There is little specific evidence exploring this, however the flipped classroom and constructivist learning style seem to align perfectly.

Although constructivist learning seems to align with the flipped classroom and deep learning, Springer et al. (1999) highlights other learning styles that seem like they are relevant to the flipped classroom. When in small groups such as the seminar it seems inevitable that there is a certain amount of social learning. Social learning is where students learn and, to an extent, copy behaviours of people around them (Springer et al. 1999). By enhancing engagement social learning theory would suggest that students will help each other to learn and to engage. Bruner (1984) discusses Vygotsky's zone of proximal learning, the theory that beginners learn from experts who are in close proximity and this is crucial in their development. In the flipped classroom, by its nature, some students will become relative 'experts' in the subject area and that will help students in the seminar to develop and could improve overall outcomes. The flipped classroom seems to retrofit this theory, however it is not an area that has been researched.

\section{$\underline{\text { Potential drawbacks }}$}

An obvious potential problem with using the flipped classroom is that a student elects not to do the pre-learning before coming to class. The consequence of this is that the student will not be at the required level of knowledge at the start of the lecture to take part in the discussion. To mitigate this risk Gilboy et al. (2015) state that the material used for pre-learning should be no longer than fifteen minutes long. That means that a fifteen minute podcast may be about the right length of time so as not to discourage students from listening to it. In addition, students can download the podcast onto their mp3 player and listen to it at their convenience, for example whilst driving, exercising or during lunch. Knowles et al. (2011) highlights the traits of adult learners, most relevant are that adult 
learners are internally motivated to learn and learn best when they are in control of their learning. Therefore, a fifteen minute pre-learning task should not discourage a student who is internally motivated and it gives the student control of where and when the learning takes place. Therefore, if a student decides not to do the pre-learning there is probably little the lecturer can do to mitigate this risk further. Furthermore, Mok (2015) states that students are more engaged using the flipped classroom because it compliments the traits of adult learners. However, this issue highlights the importance of effective student evaluation to ensure that the flipped classroom is meeting their needs.

Another drawback of the flipped classroom method is that the production of pre-learning materials can be very time consuming. Gilboy et al. (2015) highlights that the upfront time investment can be huge, however once produced they can be reused either completely or just altered slightly for next time. In addition, they found that flipped classroom was so popular amongst faculty members and students that they felt the time invested in producing material was worth it. Once pre-learning material was set up faculty members preferred this type of teaching. If teachers are enthusiastic about teaching then it seems to follow that it is more likely that students will be enthusiastic about learning.

\section{$\underline{\text { Impact on students }}$}

The primary purpose of implementing the flipped classroom is to increase student achievement. Therefore, it seemed pertinent to obtain the students' views of the flipped classroom to assess whether they felt it impacted upon their engagement, understanding and knowledge. Butt (2015) performed a survey before and after the implementation of a flipped classroom approach. He found that before the implementation the students were reluctant about it, presumably because of the concerns over investing time in doing the pre-learning before the session and uncertainty about how much it may improve their learning experience. However, after implementation the students were much more positive and most stated that they felt more engaged. Although anecdotally, when discussing the method with paramedic students before implementation, many felt that it would better meet their needs than the more traditional teaching methods that they are predominantly exposed to. This viewpoint may be a sign of Knowles et al. (2011) theory of adult learners that they are internally motivated and learn best when they are in control of their learning. This is in keeping with much of the evidence which has evaluated students' opinions of the flipped classroom in that they felt more motivated, enthused and engaged (O'Flaherty and Phillips 2015).

Wong et al. (2014) concluded that not only did pharmacy students feel more engaged and enthused by the flipped classroom technique but that it also improved student achievements and results. This study amongst other healthcare professionals demonstrates the sometimes presumed link between student engagement and achievement which is what is hoped would be the outcome for the paramedic cohort. Jarvis (2010) highlights that assessment is crucial to measure the extent to which Intended Learning Outcomes have been met. Assessment is important to measure the level of logic that has been met by the students such as which verbs have been achieved on Blooms' taxonomy (Jarvis 2010). Gilboy et al. (2015) highlight that the flipped classroom can be used to achieve all levels of intellect on Blooms' taxonomy. This suggests that flipped classroom can be used for each level of study at undergraduate level. However, it is important to assess that the intended level of understanding has been achieved as per the intended learning outcomes. A short test was given to 
students at the start of the lecture so that they could check that they were at the required level of knowledge to begin the lecture. This test was based on knowledge gained from the podcast and was mainly concerned with describing and explaining. It is during the lecture that students were to gain more understanding, application and analysis. Therefore, it would have been pertinent, at the end of the lecture, to give the students a second short formative test so that they could assess how well they could now apply and analyse the material. This would have allowed the lecturer to evaluate common pitfalls in the flipped classroom and attempt to address these issues. However, as it was, assessment was carried out informally, and possibly subjectively, by the lecturer when facilitating the discussion in the seminar. Jarvis (2010) supports this type of assessment commenting that assessment is much more about the cognitive process rather than actual knowledge. The author can identify with this viewpoint, however the danger of this type of informal assessment is that some students, possibly ones that engage less, may not be assessed and so the evaluation may conclude a falsely over-positive result. This is particularly important when considering the implementation of the change because there is a lack of good quality evidence to demonstrate a link between the flipped classroom and student achievement.

\section{Implications for education practice}

In future use of the flipped classroom, the author would use the same type of pre-learning as this seemed to work well and will have met most, if not all, of the students' needs in terms of learning styles. More thorough evaluation of the flipped classroom is warranted to explore direct links between teaching style, engagement and achievement. This could be achieved by administering a 'before and after' test. It would also be pertinent to ask for student evaluation of the flipped classroom because, as adult learners, they should have control of their learning to a large extent.

It has been evidenced that there is a great potential for using the flipped classroom in paramedic pedagogy and that it seems to fit alongside what is already known about good teaching and learning and compliments it well. There are some potential drawbacks but these can be managed and mitigated to an extent. Although a newly emerging teaching method, there is increasing evidence that the flipped classroom can be effectively used to promote the kind of learning that is required in paramedic education. 


\section{References}

Abevsekera, L. and Dawson, P. (2015) Motivation and cognitive load in the flipped classroom: definition, rationale and a call for research. Higher education research and development 34 (1): 1-14

Brandon, A and All, A. (2010). Constructivism theory analysis and application to curricula. Nursing Education Perspectives 31(2): 89-92.

Bruner, J. (1984) Vygotsky's zone of proximal learning: the hidden agenda. New directions for child and adolescent development 23: 93-97.

Butt, A. (2014) Student views on the use of a flipped classroom approach: evidence from Australia. Business education and accreditation 6(1): 33-43.

Danker, B. (2015) Approach to explore deep learning in large classrooms. Journal of education 3(1): 171-181.

Gilboy, M., Heinerichs, S. and Pazzaglia, G. (2015) Enhancing student engagement using the flipped classroom. Journal of nutirition education behaviour: 47(1): 109-114.

Jarvis, P. (2010) Adult education and lifelong learning (Online). $4^{\text {th }}$ Edition. Routledge, Abingdon

Knowles, M., Holton, E. and Swanson, R. (2011) The Adult Learner (online). Elsevier, Oxford

Mok, H. N. (2014) Teaching tip: the flipped classroom. Journal of information systems education 15 (1): 5 .

Mortimore , T. and Crozier, W. R. (2006) Dyslexia and difficulties with study skills in higher education. Studies in Higher Educatio, 21(2): 235-251.

O'Flaherty, J and Phillips, C. (2015) The use of the flipped classrooms in higher education: a scoping review. The internet and higher education 25: 85-95.

Ramsden, P. (2003) Learning to teach in higher education. $2^{\text {nd }}$ Edition. Routledge: London

Sankoff, P. (2014) Taking the instruction of law outside the lecture hall: how the flipped classroom can make learning more productive and enjoyable (for professors and students). Alberta law review 51(4): 16.

Springer, L., Stanne, M. and Donovan, S. (1999) Effects of Small-Group Learning on Undergraduates in Science, Mathematics, Engineering, and Technology: A Meta-Analysis. Review of Educational Research 69(1): 21-51.

Wong, T., Ip, E., Lopes, I. and Rajagopalan, V. (2014) Pharmacy students' performance and perceptions in a flipped teaching pilot on cardiac arrhythmias. American journal of pharmaceutical education 78 (10): 1-6. 